Published in "Plant Ecology 217(6): 751-761, 2015"

which should be cited to refer to this work.

\title{
Biogeography and evolution of seeder and resprouter forms of Erica coccinea (Ericaceae) in the fire-prone Cape fynbos
}

\author{
Fernando Ojeda Katharina B. Budde $\cdot$ Myriam Heuertz \\ José G. Segarra-Moragues · Santiago C. González-Martínez
}

\begin{abstract}
The genus Erica represents the epitome of plant biodiversity in the South African Cape fynbos with over 700 species. This genus is composed of seeder and resprouter species, but both species diversity and endemism are strongly linked to the seeder habit and concentrated in the southwestern Cape Floristic Region (CFR). Erica coccinea is a relatively abundant and widespread fynbos species whose most remarkable morphological feature is the existence of distinct seeder and resprouter forms, frequently—but
\end{abstract}

Electronic supplementary material

\section{F. Ojeda ( $\square)$}

Departamento de Biología-CeiA3, Universidad de Cádiz, Campus Río San Pedro, 11510 Puerto Real, Spain e-mail: fernando.ojeda@uca.es

K. B. Budde · M. Heuertz · S. C. González-Martínez Departamento de Ecología y Genética Forestal, Centro de Investigación Forestal, INIA, 28040 Madrid, Spain

\section{K. B. Budde}

Department of Geosciences and Natural Resource Management, University of Copenhagen, Rolighedsvej 23, 1958 Frederiksberg C, Denmark

M. Heuertz · S. C. González-Martínez INRA, UMR1202 BIOGECO: Biodiversity, Genes \& Communities, 33610 Cestas, France not always-in disjunct populations. Both higher within-population genetic diversity and among-population differentiation have been found in seeders, most likely as a consequence of the shorter generation times and faster population turnovers. Resprouters, despite being less diverse, are suspected to be ancestral. However, no solid evidence has yet been provided for the ancestrality of the resprouter form, or for the demographic processes that have determined the current distribution of genetic diversity in both regeneration forms. Here, we used microsatellites and sequences of the nuclear ribosomal internal transcribed spacers to describe the phylogeographic structure of seeder and resprouter E. coccinea populations and provide good evidence for the ancestral status of the resprouter form and the comparatively

\author{
M. Heuertz · S. C. González-Martínez \\ Université de Bordeaux, UMR1202 BIOGECO: \\ Biodiversity, Genes \& Communities, 33400 Talence, \\ France \\ M. Heuertz \\ Department of Ecology and Evolution, Université de \\ Fribourg, 1700 Fribourg, Switzerland \\ J. G. Segarra-Moragues \\ Centro de Investigaciones sobre Desertificación (CIDE- \\ CSIC/UV/GV), Moncada, 46113 Valencia, Spain \\ J. G. Segarra-Moragues \\ Departamento de Biología Vegetal, Facultad de Ciencias \\ Biológicas, Universitat de València, Burjassot, \\ 46100 Valencia, Spain
}


high rates of molecular evolution in derived seeder populations. We also reveal that mixed populations, where both seeder and resprouter individuals cooccur, were originated by secondary contacts. This study highlights the role of fire in driving accelerated diversification in seeder lineages of highly speciose CFR fynbos taxa.

Keywords Fynbos biodiversity · Internal transcribed spacers · Life-history traits $\cdot$ Molecular evolutionary rates $\cdot$ Post-fire regeneration

\section{Introduction}

The geographical pattern of population genetic variation within a species, which reflects its demographic history (Avise 2000; Hewitt 1996, 2000), may also be influenced by other factors such as the contemporary ecological landscape or its own life-history traits (Knowles 2009, and references therein). Thus, understanding the role of extrinsic (e.g. climatic fluctuations, ecological gradients) and intrinsic (life-history) processes in shaping geographical patterns of population genetic structure is critical to exploring species' evolutionary history (Knowles 2009). In this sense, a high frequency of unique or private alleles in a population or group of populations of a given species is usually taken as indicative of biogeographic origin and/or isolated refugium for that species (e.g. Hewitt 1996; Ishida and Taylor 2007; Migliore et al. 2012). However, a high frequency of private alleles has also been suggested as a signature of accelerated evolution-i.e. increased rate of molecular change - in different taxa (e.g. SegarraMoragues and Ojeda 2010; Jia et al. 2011).

The South African Cape fynbos, within the Cape Floristic Region (hereafter, CFR), is renowned for its high plant biodiversity at all spatial scales (Goldblatt and Manning 2002). A winter rainfall regime and a remarkable climatic and topographical stability since the Pliocene in the western CFR (Midgley et al. 2005; Cowling et al. 2015) have favoured high diversification and low extinction rates in fynbos taxa, thereby accounting for its outstanding biodiversity (Linder 2003; Cowling et al. 2009, 2015). Superimposed on this climatic stability is the role of fire (Cowling 1987; Schnitzler et al. 2011), which might have been a crucial component in the evolution of the pyrophytic fynbos flora since the Miocene (Bytebier et al. 2011). However, the mechanism by which a regime of recurrent fires promotes plant speciation in the CFR is poorly understood (Barraclough 2006; Schnitzler et al. 2011; Litsios et al. 2014). It could involve short generation times in fire-sensitive taxa (seeders), compared to fireresistant ones (resprouters), resulting in high rates of molecular evolution and, thereby, diversification in seeder taxa (Wells 1969). Although the generation time effect on molecular evolution in plants has been under debate (e.g. Whittle and Johnston 2003; Verdú et al. 2007; Soria-Hernanz et al. 2008), in the last few years, some robust analyses of the phylogenies of numerous lineages have undoubtedly shown higher rates of molecular changes associated with shorter generation times (Smith and Donoghue 2008; Müller and Albach 2010; Yue et al. 2010).

With ca. 700 species, the genus Erica represents the epitome of plant biodiversity in the CFR (Goldblatt and Manning 2002; Pirie et al. 2011). Most CFR Erica species occur in fynbos, associated with the recurrent presence of fire (Oliver 1991). This genus is composed of seeder and resprouter species, but the seeder habit is preponderant (ca. $90 \%$ of the species; Ojeda 1998). Exceptionally, there are also 'mixed' species that include both seeder and resprouter individuals (Ojeda 1998). Species diversity and endemism in this genus are strongly linked to the seeder habit and the geographic pattern of this biodiversity is not random, but concentrated in the southwestern CFR (Ojeda 1998; Linder 2003).

Erica coccinea L. (Ericaceae) is a relatively abundant and widespread fynbos species in the western, winter rainfall half of the CFR (Oliver and Oliver 2002). It is one of the few 'mixed' Erica species, with distinct seeder and resprouter forms (Ojeda 1998; Bell and Ojeda 1999), which occur frequently — but not always - in allopatry. These two phenotypic forms have a genetic determinism (Verdaguer and Ojeda 2002, 2005), and ontogenetic evidence indicates that the seeder form is derived from the resprouter form (Verdaguer and Ojeda 2005). Both seeder and resprouter populations of E. coccinea are common in fynbos communities of coastal mountains and hills of the southwestern CFR, whereas seeder populations are scarce to absent in more inland mountains (Fig. 1). A climatic-geographic gradient of rainfall seasonality seems to account for this apparent north-south latitudinal partitioning of seeder and resprouter populations (Ojeda et al. 2005), since 


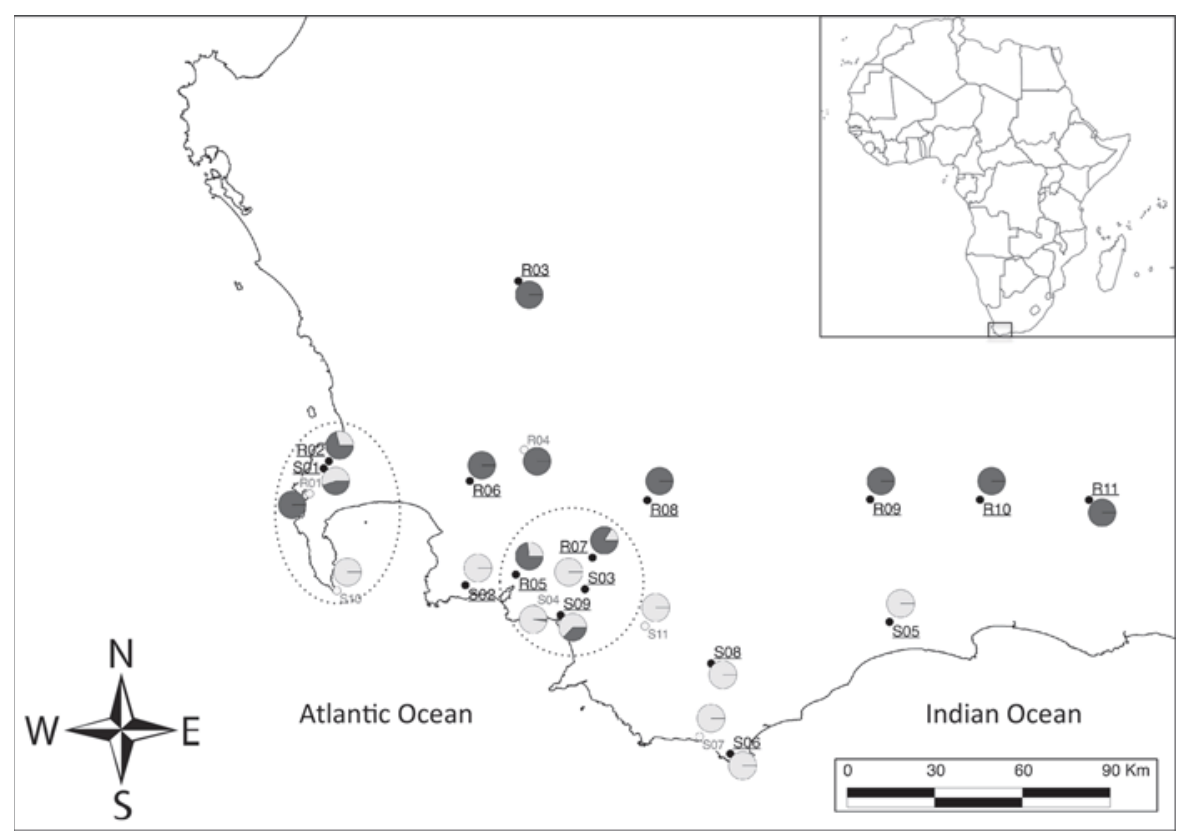

Fig. 1 Geographic distribution of Erica coccinea populations used in this study indicating the proportion of seeder (light grey) and resprouter (dark grey) regeneration forms. The Cape Peninsula (left) and Caledon (right) regions are enclosed in dotted lines. Populations used for the ITS phylogeographic analysis are marked with larger and underlined labels. Note that, for the ITS analysis, only seeder individuals were sampled from

other environmental conditions apart from rainfall seasonality (e.g. soil, mean annual rainfall, fire regime) are similar across the CFR mesic mountain fynbos (Campbell 1986; Ojeda 1998). Seeder and resprouter plants have a similar flower shape and share the orange-breasted sunbird (Anthobaphes violacea) as the main pollinator. However, their flowering phenologies hardly overlap: flowering spans from December to early June in resprouter plants (peak in January-February), and from late May to October (peak in June-July) in seeders (Malan 2013). Although both seeder and resprouter forms in this species seem to be pyrogenic recruiters, effective postfire seedling recruitment in resprouter populations is much lower (Ojeda et al. 2005; Ojeda, personal field observations). However, since resprouter adult plants survive recurrent fires by resprouting, they may experience successive post-fire recruitment episodes before they eventually die. By contrast, recruitment in seeder plants occurs as a single episode, since it is preceded by the death of adults to fire. Hence, populations of seeder E. coccinea plants are expected mixed populations $\mathrm{S} 01$ and S09, and only resprouters from R02 and R07, while both seeders and resprouters were sampled from R05 (labelled as R05s and R05r in Fig. 2). Both seeder and resprouter individuals from the five mixed populations sampled were used for the $\mathrm{ABC}$ simulations. For a more detailed location of all populations (except S11, described in the main text), see Table 1 in Segarra-Moragues and Ojeda (2010)

to have shorter generation times and faster population turnover than those of resprouters.

Segarra-Moragues and Ojeda (2010) analysed the genetic structure of seeder and resprouter populations of $E$. coccinea by means of microsatellite markers and found both higher within-population genetic diversity and higher among-population differentiation in seeders. Taking into account that both regeneration forms produce small, oval seeds and have similar, short range means of seed dispersal, these results were interpreted as a consequence of the shorter generation times and faster population turnover in seeders, resulting in higher rates of molecular change and, hence, differentiation in seeder populations (SegarraMoragues and Ojeda 2010). This microevolutionary (within species) approach thus illustrates how a regime of recurrent fires can promote diversification in seeder lineages of the genus Erica. However, Segarra-Moragues and Ojeda (2010) were not able to provide genetic evidence for the suspected ancestrality (based on ontogenetic characters; Verdaguer and Ojeda 2005) of the resprouter form, nor shed light on 
the demographic processes that have determined the current distribution of genetic diversity in both regeneration forms. Mixed populations, including both seeder and resprouter individuals, occur in the southwestern CFR (Fig. 1); whether they are dimorphic populations or the result of secondary contact between seeder and resprouter populations is also unknown.

Here, we used nuclear ITS sequences to explore the geographical pattern of genetic variation and phylogenetic relationships in seeder and resprouter populations of E. coccinea in the western half of the CFR, which represents most of its geographic range (Oliver and Oliver 2002). We also applied approximate Bayesian computation (ABC) approaches to nuclear microsatellites-complementing microsatellite data of Segarra-Moragues and Ojeda's (2010) with additional populations - to infer the evolutionary history of seeder and resprouter populations. Specifically, we aimed to (i) describe the phylogeographic structure of seeder and resprouter E. coccinea populations; (ii) provide further evidence for the ancestral status of the resprouter life form in this dimorphic species; (iii) assess the evolutionary origin of mixed populations, where both seeder and resprouter individuals cooccur; and (iv) illustrate changes in the rate of molecular evolution linked to post-fire regeneration forms. Our study provides new microevolutionary insights adding to those by Ojeda et al. (2005) and Segarra-Moragues and Ojeda (2010) to help understand the evolutionary history of the genus Erica in the CFR. Also, although extrapolation from microevolution to macroevolution must be taken with caution (e.g. Simons 2002), it emphasizes the role of fire in driving accelerated diversification in seeder lineages of highly speciose CFR fynbos taxa.

\section{Methods}

Population sampling for ITS phylogeography and microsatellite-based $\mathrm{ABC}$ analysis

Sixteen E. coccinea populations from those analysed by Segarra-Moragues and Ojeda (2010), seven seeder (S01, S02, S03, S05, S06, S08 and S09), eight resprouter (R02, R03 and R06 to R11) and one mixed (R05r/s in Segarra-Moragues and Ojeda 2010), were used for the phylogeographic analysis (Fig. 1). Two of the sampled seeder ( $\mathrm{S} 01$ and S09) and two of the resprouter populations (R02 and R07) analysed by Segarra-Moragues and Ojeda (2010) were later found to include both resprouter and seeder individuals. However, only seeder or resprouter samples, respectively, were used from them for the ITS analysis, as it was completed before that finding was made.

For the microsatellite-based ABC analysis, we used the microsatellite data from the 21 populations sampled by Segarra-Moragues and Ojeda (2010) to which we added microsatellite genotyping data of 30 seeder individuals each from R02 and R07, respectively, and of 20 and 30 resprouter individuals from S01 and S09, respectively. We also added a new seeder population (S11, Salmonsdam Nature Reserve, $34^{\circ} 25^{\prime} 22^{\prime \prime} \mathrm{S}-19^{\circ} 38^{\prime} 09^{\prime \prime} \mathrm{E}, N=36$ ). Therefore, eight resprouters (R01, R03, R04, R06, and R08-R11), nine seeders (S02-S08, S10 and S11) and five mixed populations (S01, S09, R02, R05 and R07) were considered in the ABC analyses (Fig. 1). Detailed location data for all populations (except S11) can be obtained from Segarra-Moragues and Ojeda (2010: Table 1).

DNA extraction, ITS sequencing

and microsatellite data

Fresh leaves were collected in the field and dried in silica gel. DNA was extracted using the SpeedTools plant DNA extraction kit (Biotools, Madrid, Spain). Three plastid regions ( $r b c L, t r n H-p s b A$ and $t r n C$ petN1, a total of $2489 \mathrm{bp}$ ) and the nuclear ribosomal internal transcribed spacers (ITS1-5.8s-ITS2 region, $727 \mathrm{bp}$ ) were initially screened for polymorphism in a panel of 15-18 samples following standard PCR protocols, as described in Shaw et al. (2005) for plastid regions and in Dick and Heuertz (2008) for ITSs. After amplification, PCR products were purified on filter columns (QIAquick96 kit, Qiagen, Hilden, Germany) and quantified on agarose gels $(1 \%)$. Sequencing reactions were performed in both directions using BigDye v.3.1 chemistry (Applied Biosystems, Lennik, Belgium) on an ABI3730 sequencer (Applied Biosystems). Sequences were edited and aligned in CodonCode Aligner 4.2.3. (CodonCode Corporation, Dedham, MA, USA). Only one polymorphism was found in plastid DNA (involving a single individual with $t r n H-p s b A$ ), and thus, only highly polymorphic ITS sequences were generated for the total sample. 
Table 1 Number of ribotypes (nr), ribotype diversity (rd) and private ribotypes (number of private ribotypes and frequency in the population) for resprouter and seeder populations of Erica coccinea (see Fig. 1 and Segarra-Moragues and Ojeda 2010 for geographic location)

\begin{tabular}{|c|c|c|c|c|c|}
\hline \multirow[t]{2}{*}{ Population code } & \multirow[t]{2}{*}{$N$} & \multirow[t]{2}{*}{$\mathrm{nr}$} & \multirow[t]{2}{*}{ rd } & \multicolumn{2}{|c|}{ Private ribotypes } \\
\hline & & & & Number & Frequency \\
\hline \multicolumn{6}{|l|}{ Resprouters } \\
\hline $\mathrm{R} 02$ & 5 & 2 & 0.356 & 1 & 0.20 \\
\hline R03 & 4 & 2 & 0.250 & 0 & 0.00 \\
\hline R06 & 5 & 1 & 0.000 & 0 & 0.00 \\
\hline R07 & 5 & 3 & 0.733 & 1 & 0.40 \\
\hline R08 & 4 & 1 & 0.000 & 0 & 0.00 \\
\hline R09 & 5 & 2 & 0.200 & 0 & 0.00 \\
\hline $\mathrm{R} 10$ & 6 & 2 & 0.167 & 1 & 0.08 \\
\hline $\mathrm{R} 11$ & 5 & 2 & 0.356 & 0 & 0.00 \\
\hline $\mathrm{R} 05 \mathrm{r}$ & 9 & 3 & 0.582 & 1 & 0.06 \\
\hline Average & 5.33 & 2 & 0.294 & 0.44 & 0.08 \\
\hline \multicolumn{6}{|l|}{ Seeders } \\
\hline S01 & 5 & 2 & 0.200 & 0 & 0.00 \\
\hline S02 & 4 & 3 & 0.607 & 3 & 1.00 \\
\hline S03 & 5 & 3 & 0.622 & 2 & 0.40 \\
\hline S05 & 5 & 3 & 0.711 & 2 & 0.60 \\
\hline S06 & 4 & 2 & 0.250 & 2 & 1.00 \\
\hline S08 & 5 & 2 & 0.556 & 0 & 0.00 \\
\hline S09 & 5 & 2 & 0.200 & 0 & 0.00 \\
\hline $\mathrm{R} 05 \mathrm{~s}$ & 10 & 3 & 0.542 & 1 & 0.65 \\
\hline Average & 5.37 & 2.5 & 0.461 & 1.25 & 0.45 \\
\hline
\end{tabular}

Averages by life form are also provided

Five individuals were sequenced in each population, except in the mixed R05r/s population, where 10 seeder and 10 resprouter individuals were examined. Thus, ITSs were sequenced in a total of 45 seeder and 50 resprouter individuals. Careful visual inspection of sequence chromatograms revealed that some polymorphisms contained additive polymorphic sites (APS), as expected in nuclear genes that have not undergone complete concerted evolution (Aguilar and Nieto Feliner 2003; Álvarez and Wendel 2003). Phased haploid sequences were successfully obtained using PHASE version 2.1 (Stephens and Donnelly 2003) with default parameters (see "Results"), suggesting that the ITS dataset could be interpreted in terms of biparental allelic inheritance.

Finally, nuclear microsatellite data (eight microsatellite loci) were retrieved from Segarra-Moragues and Ojeda (2010) plus the new microsatellite data from the four mixed populations and the new seeder population (see above). Microsatellite genotyping was performed as described by Segarra-Moragues and Ojeda (2010). The whole dataset included diploid genotypes for a total of 725 individuals ( 373 seeder and 352 resprouter) from 22 populations.

Phylogeographic analysis

A number of ribotypes (nr) and ribotypic diversity (rd) were computed for each population using DnaSP version 5.10 (Librado and Rozas 2009) and averaged for seeders and resprouters. Phased ITS sequences were used to construct a median-joining network using NETWORK version 4.6 (Fluxus Technology Ltd, Suffolk, UK; Bandelt et al. 1999). Finally, the geographical distribution of ITS variants was plotted using ArcMap9.3.1 (ArcGIS 9, ESRI, Redlands, CA, USA). 
Inference of ancestral life form

\section{Phylogenetic analysis}

We conducted a phylogenetic analysis on ITS sequences to explore (i) whether seeder and resprouter life forms in E. coccinea correspond to distinct ITS entities, providing supporting evidence for two taxa, and (ii) whether it could help elucidate the ancestral life form. In a previous study by Segarra-Moragues and Ojeda (2010) based on microsatellite markers, seeder and resprouter forms could not be genetically segregated. We extracted ITS data from Genbank selecting one or two sequences per major clade of the Erica genus (clades defined in Pirie et al. 2011) and including all available sequences of the " $F$ " clade to which E. coccinea belongs. We used MUSCLE ver. 3.8 software (Edgar 2004) to compute a multiple alignment of downloaded sequences and one sequence for each phased ribotype discovered in this study. For ribotypes VII, XII, XVII and XVIII, no full length ITS sequences were available, so that these ribotypes were excluded from the analysis. A first phylogenetic tree was constructed including only the phased ribotypes. In addition, a second phylogenetic tree was constructed from all unphased and phased E. coccinea sequences produced in this study and including three Erica species closely related to E. coccinea (E. cumuliflora, E. penicilliformis, and E. palliflora) for rooting purposes. Alignment curation and maximum likelihood phylogenetic analysis was then conducted using the Phylogeny.fr online pipeline (Dereeper et al. 2008) with default parameters.

\section{$A B C$ simulations}

$\mathrm{ABC}$ was used to compare alternative demographic scenarios based on the nuclear microsatellite data obtained for the 22 populations (nine seeders, eight resprouters and five mixed). Coalescent simulations were used applying two sets of models using the $\mathrm{ABC}$ framework in DIYABC v1.0.4.46beta (Cornuet et al. 2008; available at http://www1.montpellier.inra.fr/ $\mathrm{CBGP} /$ diyabc). $\mathrm{ABC}$ implementation in DIYABC allows to define the ancestral and derived branches for each splitting event, and thus, by comparison of models with different assumed ancestral populations, DIYABC can potentially provide information on ancestrality of life forms. The first set of simulations ('two-groups' models, see Fig. S1 in Supplementary Information) were then run grouping individuals by life form, to determine whether the seeder or the resprouter form was ancestral (by comparing scenarios 1 and 2 in Fig. S1A) and to compare simple models without change in effective population size with models that implemented population size changes in seeders (scenario 3 in Fig. S1A). This set of ABC simulations also included models where resprouters were grouped into western (R03, R04, R06) or eastern (R09, R10, R11) populations (see Segarra-Moragues and Ojeda 2010; Fig. S1B). A second set of simulations ('three-groups' models, see Fig. S2 in Supplementary Information) was designed to discern the origin of mixed populations from the Cape Peninsula (S01 and R02) and the Caledon region (S09, R05 and R07; see Fig. 1). In this latter case, we compared alternative demographic scenarios where mixed populations were ancestral with others where mixed populations were originated by secondary contact of distinct seeder and resprouter lineages. These simulations were run separately for the two regions with mixed populations (i.e. Cape Peninsula and Caledon regions). All priors had uniform distributions, except for mutation rates (log-uniform). Priors and summary statistics are presented in Table S1, provided as Supplementary Material. Each run consisted on 3 million simulations, distributed equally among demographic scenarios.

\section{Results}

High-quality forward and reverse ITS sequences were obtained and assembled for 91 (out of 95 sampled) individuals for an ITS region of $732 \mathrm{bp}$ (Genbank accession numbers KT898981-KT899071). Within this region, we found 14 single nucleotide polymorphisms (SNPs) and 3 indels (GT/- in position 283-284 bp, $T /$ - in position $298 \mathrm{bp}$ and $A /$ - in position $682 \mathrm{bp}$ ), which combined into 18 phased ITS ribotypes (Fig. 2; Fig. S3 and Table S2 in Supplementary Information). Most ribotypes were found in only one of the life forms, with 10 ribotypes appearing only in seeders and four only in resprouters (Fig. 2). From the remaining four ribotypes shared between both life forms (III, IV, V and IX), ribotype III was widespread but found mostly in resprouters, whereas ribotype $\mathrm{V}$ was present mostly in seeders. Ribotype IX was found 


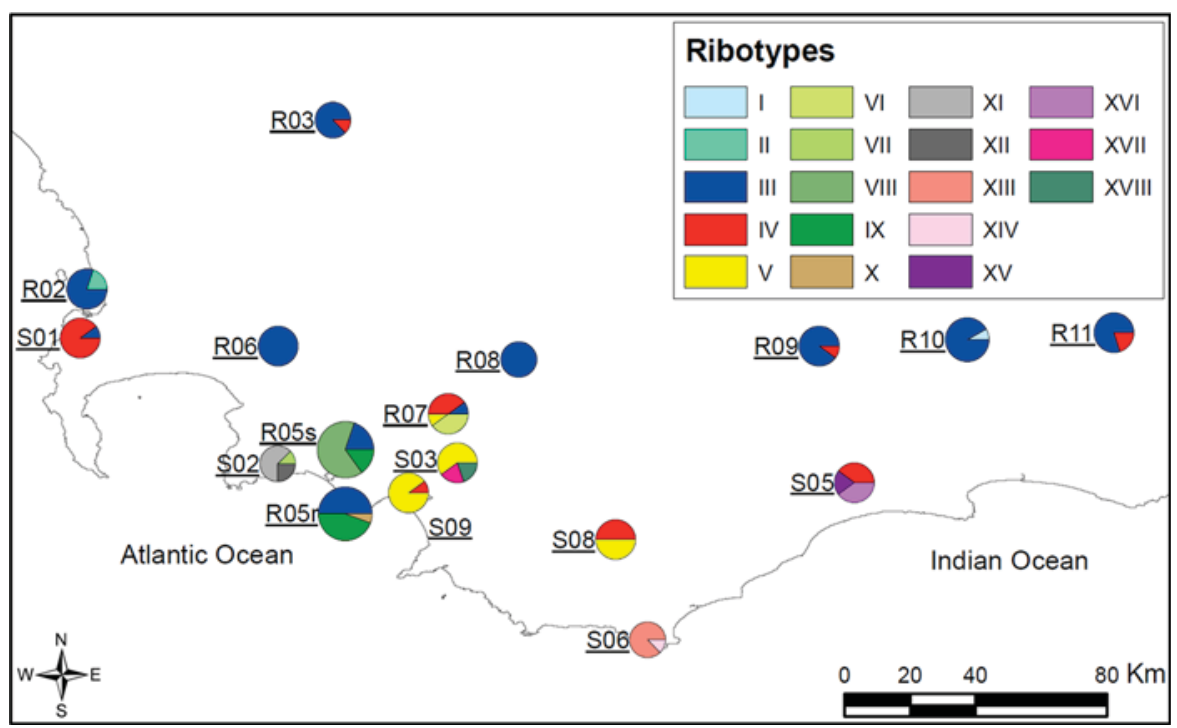

Fig. 2 Geographic distribution of 18 ITS ribotypes found in $E$. coccinea. Pie charts are proportional to sample size. Notice that a prefix ' $S$ ' indicates a seeder population and a prefix ' $R$ ' a

in the two life forms, but only in the R05 mixed population, where both seeders and resprouters were sampled. Finally, Ribotype IV (red in Fig. 2) was the only widespread ribotype that was also widely shared by the two life forms. It must be noted that, with the exception of this latter ribotype, most ribotype sharing was restricted to the Cape Peninsula and the Caledon regions, where mixed populations are found (see Fig. 1). Ribotypic diversity was higher in seeders than in resprouters (Table 1).

Seeder and resprouter ribotypes were intermingled in the median-joining network and separated by only few mutations (Fig. 3). Notably, one shared ribotype (Ribotype IV) and one resprouter ribotype (Ribotype VI, private to population R07) were central in the network. Ribotypes found in seeders, apart from being more abundant (see above), also displayed a greater evolutionary distance among each other, with a higher number of mutations between private and widespread or central ribotypes (average of 1.8 for seeders vs. 1 for resprouters). Moreover, seeder populations S02, S03, S05 and S06 were remarkable for having highly differentiated ribotypes (XII, XVIII, XVI and XIV, respectively; Fig. 3).

A phylogenetic analysis based on phased ribotypes revealed that all E. coccinea ribotypes clustered in the same clade, together with the two E. coccinea sequences available on Genbank, with unresolved resprouter population, except for R05 where both seeders (R05s) and resprouters (R05r) were sampled

relationships (Fig. S4 in Supplementary Information). A second phylogenetic analysis, including both phased and unphased ribotypes and only close outgroups, also showed unresolved phylogenetic relationships between seeders and resprouters; only two clades, one resprouter and one seeder, were distinguished with $>90 \%$ bootstrap support from a base population of both seeders and resprouters (Fig. S5 in Supplementary Information). Thus, ITS phylogenies failed to distinguish seeder and resprouter life forms as two distinct monophyletic clades, providing no support for the hypothesis that these life forms correspond to two separate taxa. It did not either resolve the ancestral life form, as the E. coccinea clade constituted a polytomy with derived ribotypes belonging to each of the two life forms in both phylogenetic trees.

The best ABC scenario for the 'two-groups' models, however, pointed to resprouters as the ancestral form, with seeders splitting from them some 3070 generations ago (95\% CIs: 774-7610 generations ago). The split of seeders from resprouters took place before western and eastern resprouter populations diverged, estimated at about 533 generations ago (95 \% CIs: 108-1250 generations ago). Interestingly, estimates of effective population size were much higher in seeders $(59,600,95 \%$ CIs: $19,500-97,400)$ than in resprouters (9580, $95 \%$ CIs: 3480-14,700). Models including effective population size changes in 
Fig. 3 Median-joining phylogenetic network. Ribotype colours and codes are the same as in Fig. 2. Circles indicate ribotypes shared between seeders and resprouters. The remaining 14 ribotypes were private to resprouter (blue labels) and seeder (orange labels) populations, in turn indicated by triangles or squares, respectively. Symbols are proportional to ribotype frequency. Black circles indicate missing or unsampled ribotypes. (Color figure online)

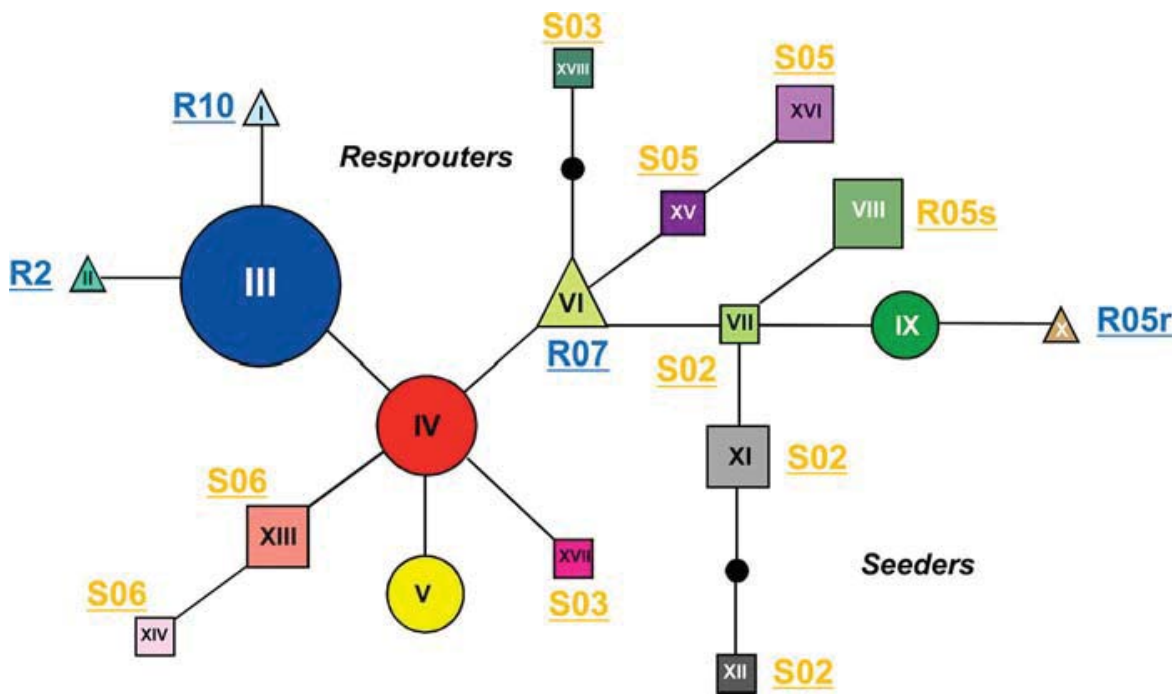

seeders provided worse fit than simpler models with constant effective population sizes. Best demographic scenarios for 'three-groups' models indicated that, for both Caledon and Cape Peninsula regions, mixed populations originated by secondary contact of distinct seeder and resprouter populations. This secondary contact was older in the Cape Peninsula (1392 generations ago, $95 \%$ CIs: 271-3680) than in the Caledon region (382 generations ago, $95 \%$ CIs: 54-1010), but involved similar admixture rates (11.1\% seeder for the Cape Peninsula and $24.1 \%$ for the Caledon region). A summary of demographic events, as suggested by ABC simulations, is presented in Fig. 4.

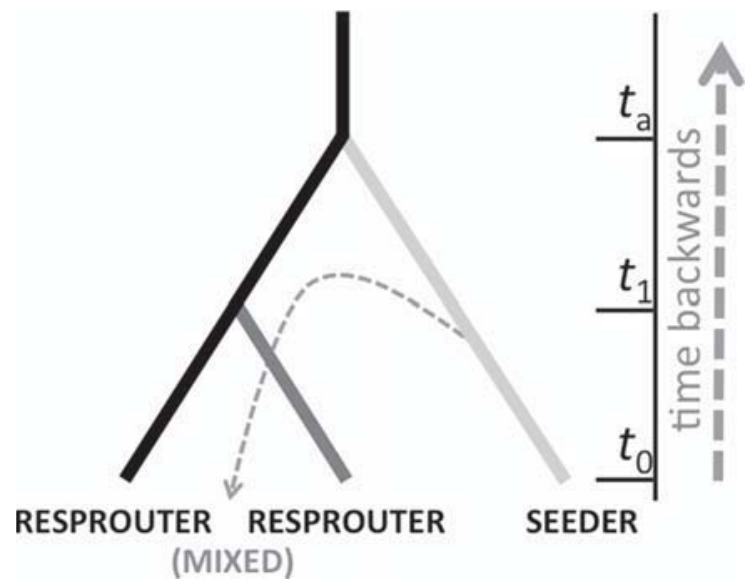

Fig. 4 Summary illustration of the demographic events affecting seeder and resprouter populations of Erica coccinea, as inferred from $\mathrm{ABC}$ simulations. Times are not scaled

\section{Discussion}

Based on nuclear ITSs, E. coccinea showed a strong phylogeographic pattern, with distinct features for seeder and resprouter life forms. Ribotypes III and IV were the most common and widespread and, under coalescent theory, likely the oldest ones (Posada and Crandall 2001). Ribotype IV was similarly distributed in seeders and resprouters, while Ribotype III was present and predominant in all resprouter populations. Another resprouter ribotype, Ribotype VI, was central in the median-joining network, despite its restricted distribution to resprouter population R07 (see Figs. 2, 3). Moreover, while seeder populations presented both high frequency of private ribotypes and high average number of mutations from common/central to private ribotypes, private ribotypes were much less frequent and never abundant in resprouter populations. Seeder populations S02, S03, S05 and S06 were remarkable for presenting highly differentiated ribotypes (Fig. 3). Population S06 actually belongs to the distinct subspecies, E. coccinea subsp. uniflora (Oliver and Oliver 2002), but populations S02, S03 and S05 belong to the type subspecies E. coccinea subsp. coccinea (Oliver and Oliver 2002) as the rest of the sampled populations, including both seeder and resprouter. So, putative taxonomic differences between seeders and resprouters-which could not be supported by the ITS phylogenetic reconstruction (Figs. S4 and S5 in Supplementary Information)cannot be argued as a likely explanation for the 
distinct ribotype patterns. The high frequency of private ribotypes in seeder populations can neither be explained by geographic isolation, since average pairwise geographic distances are actually shorter in seeder than in resprouter populations (Segarra-Moragues and Ojeda 2010), and both seeder and resprouter forms have equal pollination and seed dispersal traits (Malan 2013). A high frequency of private ribotypes has also been suggested as a signature of accelerated ITS evolution (see Jia et al. 2011). Interestingly, our results parallel the higher frequency of private microsatellite alleles in E. coccinea seeder populations reported by Segarra-Moragues and Ojeda (2010), which these authors interpreted as the result of faster rates of new alleles arising in seeder populations owing to their comparatively shorter generation times.

While phylogenetic analysis of ITS did not resolve the ancestral life form in E. coccinea, the $\mathrm{ABC}$ analysis of the microsatellite data presented in this study suggests that resprouter populations are ancestral in this species. Thus, the derived seeder state can be interpreted as the result of an ontogenetic loss of the resprouting ability (Verdaguer and Ojeda 2005), likely as a consequence of a loss-of-function mutation. The 'mutant' seeder phenotype would have replaced an originally resprouter population under particular environmental conditions associated with a stable, mild Mediterranean climate (Ojeda et al. 2005), characteristic of the southwestern CFR at least since the early Pleistocene (Verboom et al. 2014). The ABC analysis dated this branching event some 3000 generations before present, i.e. about 60,000 years ago assuming 20-year fire return intervals (Ojeda et al. 2005). Interestingly, this dates back to the penultimate Pleistocene glaciation, when the Agulhas Bank was exposed above the sea level, providing new opportunities for plant diversification (Cowling et al. 2009; Verboom et al. 2014). During this period, owing the lower temperatures and more regular frontal rains (Midgley et al. 2005; Marean et al. 2014), Mediterranean climate in the southwestern CFR was probably milder, a feature which would have favoured seeders (Ojeda et al. 2005).

Moreover, according to the $\mathrm{ABC}$ simulations, the subdivision of resprouter E. coccinea populations into western and eastern groups (Segarra-Moragues and Ojeda 2010) occurred more recently than the appearance of the seeder form and, at about the same time, they came into secondary contact with seeders. This contact happened some 1300 generations ago in the Cape Peninsula and more recently in the Caledon region, likely as a consequence of environmental changes that favoured the expansion and genetic differentiation of seeder populations across coastal mountains of the southwestern CFR. Coincidentally, 1300 generations (i.e. 26,000 years) ago dates back to the Last Glacial Maximum when, once again, the Agulhas Bank emerged (Verboom et al. 2014) and the Mediterranean climate was again milder (Midgley et al. 2005; Marean et al. 2014) and, hence, more suitable for seeders in the southwestern CFR (Ojeda et al. 2005). This seeder expansion could not reach the NW nor the SE of the CFR because of the demographic constraints of seeder populations under either strongly seasonal or non-seasonal regimes (Ojeda et al. 2005), thus accounting for the lack of seeder and mixed populations further inland within the CFR (Fig. 1).

It must be stressed that most shared ribotypes between seeders and resprouters were found within or close to mixed populations, suggesting that a relatively recent secondary contact and subsequent gene flow may account for this ribotype sharing. Similar patterns of introgressive gene flow after secondary contact of previously separated lineages have been found in other plant species (e.g. in temperate or tropical trees, Latta and Mitton 1999; Born et al. 2008). Although the flowering phenologies of seeder and resprouter $E$. coccinea populations hardly overlap (see "Introduction"), there may still be-or could have been in the recent past-some opportunities for hybridization and gene flow across regeneration forms. Nevertheless, this must be further investigated (e.g. using genomic approaches), since common ancestry rather than secondary contact may still underlie some of the shared ribotypes. Ancestral shared polymorphism has also been repeteadly reported in different plant taxa (e.g. Bouillé and Bousquet 2005; Blanco-Pastor et al. 2012).

Apart from the undeniable importance of geological and climatic stability for understanding the high biodiversity of the CFR flora (Schnitzler et al. 2011; Cowling et al. 2015), fire has also been suggested as one of the key causal factors (Cowling 1987; Ellis et al. 2014). However, the mechanism by which firedriven diversification has occurred has been explained only in terms of the evolution of the two fire regeneration forms, seeder and resprouter, in sister 
species (Schnitzler et al. 2011; Ellis et al. 2014). This study provides additional microevolutionary insights to those by Segarra-Moragues and Ojeda (2010), not only to help understand the evolutionary history of the genus Erica in the CFR, but also to understand how fire may have spurred diversification in seeder lineages of pyrophytic fynbos taxa (McDonald et al. 1995).

Acknowledgments This contribution is dedicated to the memory of Peter Clarke, whose passionate interest in the evolutionary relationships between plants and fire has been so contagious and inspiring. The manuscript benefited greatly from comments by two anonymous referees. Cape Nature and SANPARKS issued the necessary permits for fieldwork. FO strongly thanks the Spanish Ministerio de Educación (travel Grant PR2010-0365) and the UCA Plan Propio de Investigación for providing travelling bursaries to do fieldwork. KBB acknowledges a PhD scholarship (FPI, BES-2009-015443) of the Spanish Ministry of Science and Innovation (MICINN). MH acknowledges a Ramón y Cajal fellowship (RYC2009-04537) from the Spanish Ministry of Science and Education (MICINN), and funding from the Research Council of Norway (203822/E40) and the Spanish Ministry of Economy and Competitiveness (CGL2012-40129-C02-02). SCGM and MH acknowledge the support of Marie Curie Intra European Fellowships within the 7th European Community Framework Programme (FP7-PEOPLE2012-IEF, project nos. 328146 and 329088, respectively). JGS-M acknowledges a Ramón y Cajal fellowship (RYC2009-05164) from MICINN.

\section{References}

Aguilar JF, Nieto Feliner G (2003) Additive polymorphisms and reticulation in an ITS phylogeny of thrifts (Armeria, Plumbaginaceae). Mol Phylogenet Evol 28:430-447

Álvarez I, Wendel JF (2003) Ribosomal ITS sequences and plant phylogenetic inference. Mol Phylogenet Evol 29:417-434

Avise JC (2000) Phylogeography: the history and formation of species. Harvard University Press, Cambridge

Bandelt H, Forster P, Röhl A (1999) Median-joining networks for inferring intraspecific phylogenies. Mol Biol Evol $16: 37-48$

Barraclough TG (2006) What can phylogenetics tell us about speciation in the Cape flora? Divers Distrib 12:21-26

Bell TL, Ojeda F (1999) Underground starch storage in Erica species of the Cape Floristic Region-differences between nonsprouters and resprouters. New Phytol 144:143-152

Blanco-Pastor JL, Vargas P, Pfeil BE (2012) Coalescent simulations reveal hybridization and incomplete lineage sorting in Mediterranean Linaria. PLoS One 7(6):e39089

Born C, Hardy OJ, Chevallier MH, Ossari S, Attéké C, Wickings EJ, Hossaert-Mckey M (2008) Small-scale spatial genetic structure in the Central African rainforest tree species
Aucoumea klaineana: a stepwise approach to infer the impact of limited gene dispersal, population history and habitat fragmentation. Mol Ecol 17:2041-2050

Bouillé M, Bousquet J (2005) Trans-species shared polymorphisms at orthologous nuclear gene loci among distant species in the conifer Picea (Pinaceae): implications for the long-term maintenance of genetic diversity in trees. Am J Bot 92:63-73

Bytebier B, Antonelli A, Bellstedt DU, Linder HP (2011) Estimating the age of fire in the Cape flora of South Africa from an orchid phylogeny. Proc R Soc Lond Biol 278:188-195

Campbell BM (1986) Montane plant communities of the Fynbos Biome. Vegetatio 66:3-16

Cornuet JM, Santos F, Beaumont MA, Robert CP, Marin JM, Balding DJ et al (2008) Inferring population history with DIYABC: a user-friendly approach to approximate Bayesian computation. Bioinformatics 24:2713-2719

Cowling RM (1987) Fire and its role in coexistence and speciation in Gondwanan shrublands. S Afr J Sci 83:106-112

Cowling RM, Potts AJ, Bradshaw PL, Colville J, Arianoutsou M, Ferrier S, Forest F, Fyllas NM, Hopper SD, Ojeda F, Proches S, Smith RJ, Rundel PW, Vassilakis E, Zutta BR (2015) Variation in plant diversity in mediterranean-climate ecosystems: the role of climatic and topographical stability. J Biogeogr 42:552-564

Cowling RM, Proches S, Partridge TC (2009) Explaining the uniqueness of the Cape flora: incorporating geomorphic evolution as a factor explaining its diversification. Mol Phylogenet Evol 51:64-74

Dereeper A, Guignon V, Blanc G, Audic S, Buffet S, Chevenet F et al (2008) Phylogeny.fr: robust phylogenetic analysis for the non-specialist. Nucleic Acids Res 36:W465-W469

Dick CW, Heuertz M (2008) The complex biogeographic history of a widespread tropical tree species. Evolution 62:2760-2774

Ellis AG, Verboom GA, van der Niet T, Johnson SD, Linder HP (2014) Speciation and extinction in the Greater Cape Floristic Region. In: Allsopp N, Colville JF, Verboom GA (eds) Fynbos: ecology, evolution and conservation of a megadiverse region. Oxford University Press, Oxford, pp 119-141

Edgar RC (2004) MUSCLE: multiple sequence alignment with high accuracy and high throughput. Nucleic Acids Res 32:1792-1797

Goldblatt P, Manning JC (2002) Plant diversity of the Cape region of southern Africa. Ann Missouri Bot Gard $89: 281-302$

Hewitt GM (1996) Some genetic consequences of ice ages, and their role in divergence and speciation. Biol J Linn Soc $58: 247-276$

Hewitt GM (2000) The genetic legacy of the Quaternary ice ages. Nature 405:907-913

Ishida S, Taylor DJ (2007) Quaternary diversification in a sexual Holarctic zooplankter, Daphnia galeata. Mol Ecol 16:569-582

Jia DR, Liu TL, Wang LY, Zhou DW, Liu JQ (2011) Evolutionary history of an alpine shrub Hippophae tibetana (Elaeagnaceae): allopatric divergence and regional expansion. Biol J Linn Soc 102:37-50

Knowles LL (2009) Statistical phylogeography. Annu Rev Ecol Evol Syst 40:593-612 
Lamont BB, Enright NJ, He T (2011) Fitness and evolution of resprouters in relation to fire. Plant Ecol 212:1945-1957

Latta RG, Mitton JB (1999) Historical separation and present gene flow through a zone of secondary contact in ponderosa pine. Evolution 53:769-776

Librado P, Rozas J (2009) DnaSP v5: a software for comprehensive analysis of DNA polymorphism data. Bioinformatics 25:1451-1452

Linder HP (2003) The radiation of the Cape flora, southern Africa. Biol Rev 78:597-638

Litsios G, Wüest RO, Kostikova A, Forest F, Lexer C, Linder HP, Pearman PB, Zimmermann NE, Salamin N (2014) Effects of a fire response trait on diversification in replicated radiations. Evolution 68:453-465

Malan MC (2013) Intraspecific variation in Erica coccinea. MSc Thesis, University of Cape Town, South Africa. https://open.uct.ac.za/handle/11427/6672

Marean CW, Cawthra HC, Cowling RM, Esler KJ, Fisher E, Milewski A, Potts AJ, Singels E, De Vynck J (2014) Stone age people in a changing South African greater Cape Floristic Region. In: Allsopp N, Colville JF, Verboom GA (eds) Ecology and evolution of fynbos: understanding megadiversity. Oxford University Press, Oxford, pp 164-199

Mcdonald DJ, Juritz JM, Cowling RM, Knottenbelt WJ (1995) Modelling the biological aspects of local endemism in South African Fynbos. Plant Syst Evol 195:137-147

Midgley GF, Reeves G, Klak C, Richardson J (2005) Late tertiary and quaternary climate change and centers of endemism in the southern African flora. In: Purvis A, Gittleman J, Brooks T (eds) Phylogeny and conservation. Cambridge University Press, Cambridge, pp 230-242

Migliore J, Baumel A, Juin M, Médail F (2012) From Mediterranean shores to central Saharan mountains: key phylogeographical insights from the genus Myrtus. J Biogeogr 39:942-956

Müller K, Albach DC (2010) Evolutionary rates in Veronica L. (Plantaginaceae): disentangling the influence of life history and breeding system. J Mol Ecol 70:44-56

Ojeda F (1998) Biogeography of seeder and resprouter Erica species in the Cape Floristic Region-where are the resprouters? Biol J Linn Soc 63:331-347

Ojeda F, Brun FG, Vergara JJ (2005) Fire, rain, and the selection of seeder and resprouter life-histories in fire-recruiting, woody plants. New Phytol 168:155-165

Oliver EGH (1991) The Ericoideae (Ericaceae)—a review. Contrib Bolus Herb 13:158-208

Oliver EGH, Oliver IM (2002) The genus Erica (Ericaceae) in southern Africa: taxonomic notes 1. Bothalia 32:37-62

Pirie MD, Oliver EGH, Bellstedt DU (2011) A densely sampled ITS phylogeny of the Cape flagship genus Erica L. suggests numerous shifts in floral macro-morphology. Mol Phylogenet Evol 61:593-601
Posada D, Crandall KA (2001) Intraspecific gene genealogies: trees grafting into networks. Trends Ecol Evol 16:37-45

Schnitzler J, Barraclough TG, Boatwright JS, Goldblatt P, Manning JC, Powell MP, Rebelo T, Savolainen V (2011) Causes of plant diversification in the Cape biodiversity hotspot of South Africa. Syst Biol 60:343-357

Segarra-Moragues JG, Ojeda F (2010) Postfire response and genetic diversity in Erica coccinea: connecting population dynamics and diversification in a biodiversity hotspot. Evolution 64:3511-3524

Shaw J, Lickey EB, Beck JT, Farmer SB, Liu W, Miller J, Siripun KC, Winder CT, Schilling EE, Small RL (2005) The tortoise and the hare II: relative utility of 21 noncoding chloroplast DNA sequences for phylogenetic analysis. Am J Bot 92:142-166

Simons AM (2002) The continuity of microevolution and macroevolution. J Evol Biol 15:688-701

Smith SA, Donoghue MJ (2008) Rates of molecular evolution are linked to life history in flowering plants. Science 322:86-89

Soria-Hernanz DF, Fiz-Palacios O, Braverman JM, Hamilton MB (2008) Reconsidering the generation time hypothesis based on nuclear ribosomal ITS sequence comparisons in annual and perennial angiosperms. BMC Evol Biol 8:344

Stephens M, Donnelly P (2003) A comparison of Bayesian methods for haplotype reconstruction from population genotype data. Am J Hum Genet 73:1162-1169

Verboom GA, Linder HP, Forest F, Hoffmann V, Bergh NG, Cowling RW (2014) Cenozoic assembly of the Greater Cape Flora. In: Allsopp N, Colville JF, Verboom GA (eds) Fynbos: ecology, evolution and conservation of a megadiverse region. Oxford University Press, Oxford, pp 93-118

Verdaguer D, Ojeda F (2002) Root starch storage and allocation patterns in seeder and resprouter seedlings of two Cape Erica (Ericaceae) species. Am J Bot 89:1189-1196

Verdaguer D, Ojeda F (2005) Evolutionary transition from resprouter to seeder life history in two Erica (Ericaceae) species: insights from seedling axillary buds. Ann Bot 95:593-599

Verdú M, Pausas JG, Segarra-Moragues JG, Ojeda F (2007) Burning phylogenies: fire, molecular evolutionary rates, and diversification. Evolution 61:2195-2204

Wells PV (1969) The relation between mode of regeneration and extent of speciation in woody genera of the California chaparral. Evolution 23:264-267

Whittle CA, Johnston MO (2003) Broad-scale analysis contradicts the theory that generation time affects molecular evolutionary rates in plants. J Mol Evol 56:223-233

Yue JX, Li J, Wang D, Araki H, Tian D, Yang S (2010) Genomewide investigation reveals high evolutionary rates in annual model plants. BMC Plant Biol 10:242 